\title{
La réaction Bordet-Wassermann de 1231 liquides céphalo-
} rachidiens

Clinique dermatologique universitaire de Genève (Prof. Dr. W. Jadassohn)

Les cliniques et policliniques de Geneve ont envoyé en 26 mois 1231 liquides céphalo-rachidiens pour la reaction de Bordet-Wasser-mann.

3,5\% étaient positifs; 6,3\% n’étaient pas complètement négatifs. Parmi les 34 liquides céphalorachidiens douteux ou presque négatifs il y en avait 11 sans autres signes de syphilis. Les malades dont provenaient ces 11 liquides étaient au moment de la ponction dans un état cerebral grave.

Sur 12 cas de tabes et paralysie générale avec liquide céphalo-rachidien non négatif, connaissant I’année de l'infection, il n’y en a pas un qui dit s'être infecté après 1932.

19 syphilitiques avec liquide céphalo-rachidien non négatif disent avoir été traités presque tous d'une manière tout à fait insuffisante; 48 observations ne nous donnent aucun renseignement sur un traite-ment antérieur.

A para in extenso dans la Revue médicale de la Suisse Romande LXIX, p. 439, (1949).

Über Hautveränderungen bei der Ratte nach großen oralen Dosen von Vitamin A

Von A. STUDER und J. R. FREY Erschien in der Schweiz. Med. Wochenschrift 1949, 382. 